\title{
The Problem of Universals: A Re-examination
}

\author{
Dr. Chhanda Chatterjee ${ }^{1}$, Dr. Amiya Chatterjee ${ }^{2}$ \\ ${ }^{1,2}$ Department of Philosophy, Balurghat College, West Bengal, India
}

\begin{abstract}
The controversy between realism and anti realism regarding the objective existence universals takes the different shapes in different times. In contemporary western philosophy the problem of universals is formulated as the problem of the application of general words. Wittgenstein introduces the concept of family resemblance as an alternative explanation and claims that without postulating the objective universals the problem of the application of general words can easily be solved. We have tried to show in this paper whether Wittgenstein's theory of family resemblance have solved the problem of universals.
\end{abstract}

Keywords : Family Resemblance, General term, Realism, Universals, Wittgenstein

\section{Introduction}

The age old controversy between realism and anti-realism-whether the universals are ontological realities or mere empty names with no reality affixed to them-received a new direction in contemporary philosophy when a group of anti-realists came forward with a novel weapon usually branded as the Resemblance theory to combat the realistic theory of universals. The doctrine of universals advocated by realists may be designated as Identity theory, because it maintains that the universals are common characters, i.e., qualities, relations etc, which repeats themselves identically in or between the individual members of a given class of objects. Contrasted with the general metaphysical orientation of the realistic theory of universals, the resemblance theory proclaims that the so-called 'metaphysical' universals are to be totally dispensed with as redundant hypothesis in explaining the ultimate structure of the universe. Because the mere fact of observed resemblance among different particular objects of nature, which alone are existent entities, is sufficient to solve all the problems. The purpose of the present paper is to give a clear exposition and analysis as how far this ambitious claim of the anti-realist to substitute the infinite variety of universals [1] by a single category of resemblance is a realisable project. But this requires at the outset a preliminary survey of the foundational reasons on which the realistic theory of universals is supposed to rest.

\section{The arguments for postulating objective universals.}

The realists postulates the objective existence of universals mainly for three reasons: (i) The universals provide an objective basis for the classification of natural objects (ii) The universals constitute the ontological foundation which makes conceptual cognition possible (iii) The objective universals justify the significant use of general words.

\subsection{The classification of natural objective}

The realists hold that the external nature which confronts us in our every day experience is not a just anomalous amalgam of individual objects but seems to be neatly organized into several 'kinds' or 'classes' the member of which share some identical features in common. All the white objects of the world, for example, form a distinct class of their own because the quality whiteness is found to be repeated identically each of them. If the objects of the world, hold the realists, were unique in their own way having nothing in common, then no laws could be promulgated about them, no generalization could be made and consequently the progress of science and knowledge in general, which obviously depends on generalization, would come to stand still. But the enormous progress made in the field of science points to the fact that generalization about the objects of nature is possible, or the promulgation of laws relating to the behaviour of natural objects is an attainable goal. But this could never have done unless things of nature were classified into several kinds by virtue of their possession of certain identical features in common. Thus, the realists conclude that the universals are genuine ontological identities which provide an objective foundation for the classification of and generalization about the objects of nature.

\subsection{The possibility of conceptual cognition.}

The realists argue that unless there are recurrent universals in the shape of identical qualities and relations, our conceptual cognition could never have started. The possibility of conceptual cognition is a basic assumption for both science and philosophy, and the objective existence of universals makes such conceptual 
cognition possible. In a world of perpetual flux where no quality repeats itself or no relation occurs, no concept could ever be acquired; or even if they could be obtained innately without needing to acquire them, they could never have been applied to anything. Acquisition and application of concepts presuppose recurrent identity, in some form or other, in the objective world. A perpetually changing world characterized by the non-recurrence of any identical qualities or relations cannot be conceptually thought about but only immediately experienced in a kind of incommunicable mystic intuition.

\subsection{The significant use of general term.}

Any language is composed of words and the words in a given language can be conveniently divided into two classes, namely, proper names and general words. A proper name refers to a particular person, thing or place whose name it is. For example, the word 'Santiniketan' or 'Rabindranath Tagore' refers to a particular place or a particular person. But the general words refer not to one particular person or particular place. Their whole point and usefulness is that they can be applied to any one of a whole range of particular objects, things, events or situations. The word 'man' or 'city' refers not to any particular man or particular city one cares to take. The question naturally arises - where from do these general words derive their generality? How is it possible that a single word can refer to a set of entities in general? The answer given by the realists is that they can do so by virtue of the fact that the individual members of a given class share an identical quality or relation in common, and just as proper names refer to the discrete individuals in their unique individuality so the general names refer to these common identical qualities shared by the individuals. On this theory, there will be no distinction in principle between a proper name and a general word so far as their function in a given language is concerned. Both of them refer to one and only one thing, though the 'thing' referred to by the proper name will be ontologically different from that referred to by general word. In the former case it would be a unique individual, in the latter case it would be an identical quality or relation shared by the individuals. Thus, any successful use of general words, holds a realist, presupposes recurrent identities in the objective world.

\section{Anti-realists Approach : The Resemblance theory}

The Resemblance theory amounts to be a common sense view and it proclaim that the so called 'metaphysical' universals are to be wholly dispensed with as redundant hypothesis in explaining the ultimate structure of the universe. It asserts that the features or qualities of any given object are as particular and localized as the object itself. No properties can belong to two different individuals at the same time, since properties of different individuals are numerically different from one another. The white colours in different white objects, for example, are numerically different from each other, yet we do and can apply the same general term 'white' to each of them simply because all of them closely resemble certain standard white objects or class-exemplars as they are sometimes called. "Every class has, as it were, a nucleus, an inner ring of key-members, consisting of a small group of standard objects or examples" [2]. But what particular members of a given class constitute the exemplars of that class entirely depends upon our arbitrary decision or choice. The exemplars for the class of white things might be a bunch of jesmine flowers, scarps of white clouds flouting in the autumn sky, a bit of white chalk or a pieces of white paper. All these objects resemble themselves closely in being white and their resemblance is immediately given to our experience. Thus if we have once chosen the class exemplars, we can ask whether the other members of the class resemble these class exemplars as closely as they resemble one another. It they do, we apply the general term 'white' to each of them.

\subsection{The concept of Family Resemblance}

Wittgenstein in his The Blue and Brown Books [3] and Philosophical Investigations [4] reformulates the resemblance theory and introduces the concept of 'family resemblances' in order to attack the realistic claim that a general word is applied to a group of particulars on the basis of self identical repeatable property or set of properties. He holds that it is our general tendency to find something common to all entities which we commonly subsume under a general term. But these phenomena have no one thing in common which makes us use the same word to different entities. We do and can apply the same general word to different individuals, not because the individuals share some identical features in common but because overlapping similarities of properties. These similarities, Wittgenstein calls 'family resemblances', because " the various resemblances between members of a family: build, failures, colour of eyes, gait, temperament etc. etc. overlap and criss cross in the same way"[5].

Wittgenstein says that we are usually in a habit to elicit some common element in a group of similar objects. For example, we tend to grasp something in common to all horses, to all tables, to all men, to all games, to all religious, and so on, This 'craving for generality' constitutes the 'craving for essences'. But if we study how the words are actually used in ordinary language, we discover that the situations in which a word is applied have no essences in common - there are only family resemblances between them. In his Blue Book 
Wittgenstein says : "The tendency to look for something in common to all the entities which we commonly subsume under a general term.- We are inclined to think that there must be something in common to all games, say, and that this common property is the justification for applying the general term "game" to the various games; where as games form a family the members of which have family likeness. Some of them have the same nose, these the same eyebrows and others again the same way of walking; and these likenesses overlap"[6]. Again in the Philosophical Investigations he says, "Don't say: There must be something common, or they would not be called 'games' - but look and see there is anything common to all. - For if you look at them you will not see something that is common to all, but similarities, relationships, and a whole series of them at that" [7]. Let us take for example the word 'game'. The word 'game' has no unitary meaning, i.e., it is not defined by some certain conditions. There are group of characteristics found in different games - the rule bound activities, the possibility of winning and loosing, the need to exercise certain skills by the players, competition between players, some sort of joy or fun, and so on. We may call these characteristics $C_{1}, C_{2}, C_{3}, C_{4} \ldots \ldots C_{n}$. Not all games have all these characteristics. One game may have $\mathrm{C}_{1}, \mathrm{C}_{3}, \mathrm{C}_{6}$, another may have $\mathrm{C}_{1}, \mathrm{C}_{2}, \mathrm{C}_{7}$, another only $\mathrm{C}_{2}$ and $\mathrm{C}_{3}$ and so on. Thus when we pass from one game to another we find that some features remain the same, some features disappear and some new features crop up.

What Wittgenstein seeks to establish is that the activities called 'game' have no common properties in virtue of which we apply the same word to them all. If we carefully look at various games, we can see that the dogma, one uncritically and perhaps unconsciously accepts, that they must have something in common is preposterous. Thus the term 'game' cannot be defined in terms of necessary and sufficient conditions. There are no common properties or essences in various games but rather there is only "a complicated network of similarities overlapping and criss-crossing: sometimes overall similarities, sometimes similarities of detail"[8].

Wittgenstein's account of explanation of meaning allows us to bypass any appeal to the traditional scheme of definition. He identifies the meaning of words with their uses and tries to remove certain misconception about language. The tendency to treat, words abstractly — that is, to ask 'what is time?' or 'what does time mean?'-is one of the devastating errors committed by philosophers. These questions if treated abstractly, only reinforce the illusion that the meaning of a word is the essence or a mysterious entity of some sort. But Wittgenstein suggests us to consider the words more concretely, in context, in the framework of actual situations in which they occur.

\subsection{Two interpretations of the concept of family resemblance}

There are two interpretations of the concept of family resemblances. According to first interpretation there are properties common to different particulars of one kind, but they are not common to all of them. For example, there may be a property or set of properties common to all board games but there is no property common to all games. This interpretation is also suggested by Wittgenstein's simile of the thread. "And the strength of the thread does not reside in the fact that some one fibber runs through its whole length, but in the overlapping of many fibres" [9]. Prof. Sibjiban Bhattacharya says [10] that if we want to find what in common to all particulars of one kind, we do not get any single property or set of properties but only a very complicated structure of overlapping properties. This complicated structure can not be simplified to reveal any simple order.

According to second interpretation there is no common property, not even any property common only to a few particulars, but there are similarities among things denoted by the same word. These similarities are complex and the things which are similar may yet form a family without possessing any property in common, and the same word may apply to them all by virtue of these similarities [11].

\subsection{Arguments in favour of Family Resemblance theory}

Bambrough in his paper [12] supports both the above two interpretations and claims that Wittgenstein solved the problem of universals. Bambrough argues that when we try to say that games have in common, we cannot find anything. This is not because what we are looking for lies deeply hidden, but because it is too obvious to be seen. He interprets the concept of family resemblances in the following way. "We may classify a set of objects by reference to the presence or absence of feature ABCDE. It may well happen that five objects e $\mathrm{d} \mathrm{c} \mathrm{b}$ a are such that each of them has four of these properties and lacks the fifth, and the missing feature is different in each of the five cases"[13]. He illustrates the situation in the following diagram.

$\begin{array}{ccccc}e & d & c & b & a \\ A B C D & \text { ABCE } & \text { ABDE } & \text { ACDE } & \text { BCDE }\end{array}$

From the above diagram, we may say that how natural it might be to apply the same word to a number of objects which have no feature in common. Bambrough suggests, without explicitly stating it, that family resemblances can be analyzed in accordance with this model. It might of course happen that one of the objects (say b) does not exist. Then all the remaining objects have, as a matter of fact, the feature B in common. But, according to Bambrough, it will then not be in virtue of the presence of this common feature that all the objects are called by the same name since this name also applies to possible objects which lack this feature. Thus, the presence of B 
is not necessary in order that an object will be called by the name in question, and it is not sufficient either. According to this assumption an object must have four of the features A B C D E in order to be called by this name. Many objects have the feature $\mathrm{B}$ without being called by this name.

The above description of family resemblances further seems to suggest that there will be some features held in common between some of the family's members. The necessity of this stipulation, however, is brought into question when Bambrough says about 'the Churchill face' which is strikingly and obviously present in each of ten members of the Churchill family. He suggests that the features of the Churchill face, such as cleft chin, are themselves only cleft chins because they exhibit accident family resemblance. For him, what goes faces also goes for features and all the cleft chins have nothing in common except that they are cleft chins. Hence even when two members of the same family have cleft chins, it still can not be said that they share some features in common. Thus Bambrough say "there is a good sense in which no two members of the Churchill family need have any feature in common in order for all the members of the Churchill family to have the Churchill face"[14], for whatever feature we suggest as candidate for the common feature, that feature itself could undergo the same analysis.

Now the question is, how we decide whether a given concept is a family concept. In the Blue and Brown Book and in Philosophical Investigations, Wittgenstein gives many examples of concepts that he regards as family concepts, but he has not given a complete list of them. Bambrough thinks that Wittgenstein regarded all concepts as family concepts. But commentators like Ayer and Strawson think that Wittgenstein wished to draw a distinction between two kinds of concepts - those which are family concepts and those which are not. But in support of his thesis, Bambrough criticizes Ayer and Strawson, both of whom have tried to formulate, though in different ways, the distinction between family concepts and other concepts.

A.J. Ayer [15] tries to contrast the word 'game' with the word 'red'. He says that "where as there is a simple and straightforward resemblance between the things whose colour we call 'red', the sort of resemblance that leads us naturally to talk of their having an identical quality, there is no such resemblance between the things that we call 'games'.'[16] Ayer claims that the point which Wittgenstein's argument brings out is that the resemblance between the things to which the same word applies may be of different degrees. It is looser and less straight forward in some cases than in others. Thus Ayer concludes that Wittgenstein makes a contrast between simple and complex concepts by his theory of family resemblances.

But Bambrough argues that in his formulation of the doctrine family resemblances, Wittgenstein does not draw the contrast between different kinds of concepts. He says that in the Blue Book Wittgenstein asks, " could you tell me what is in common between a light red and a dark red?" [17] In the Philosophical Investigations he further asks "which shade is the 'sample in my mind' of the colour green — the sample of what is common to all shades of green?" [18]

Here Bambrough seems to thinks that Wittgenstein's reason for asking these questions is that red (or green) objects do not share any feature in common but are related to each other by family resemblances. He claims that Wittgenstein could as easily have used the example of red things as the example of games to illuminate the tendency to look for something in common to all the entities subsumed under a general term. He argues "just as cricket and chess and patience and ring-a-ring-a-roses have nothing in common except that they are games, so poppies and blood and pillar-boxes and hunting-coats have nothing in common except that they are red." [19]

Wennerberg argues [20] that Wittgenstein does not subscribe to this view. According to Wittgenstein it is a mistake to think that if we define a colour-word, say 'green', to a person ostensively and he understands the definition, then he must have in his mind and idea of the thing defined - an idea of what is common to all shades of green. If the person continues to apply the word 'green' correctly, we will say that he has seen what the objects we showed him had in common. The criterion for asserting that a person has seen what the objects falling under a certain concept have in common is that he uses the word correctly. Thus it appears that even if we agree to hold that the contrast, as made by Ayer, between different kinds of concepts was not drawn by Wittgenstein, yet Bambrough does not succeed to prove that Wittgenstein regards colour concepts as family concepts.

Now let us discuss Bambrough's criticism of Strawson. Bambrough thinks that in Individuals, Strawson makes a distinction between two kinds of complex concepts, those which are definable in terms of necessary and sufficient conditions and those which are not. In Individuals, Strawson says: "It is often admitted, in the analytical treatment of some fairly specific concept, that the wish to understand is less likely to be served by the search for a single strict statement of the necessary and sufficient conditions of its application than by seeing its applications - in Wittgenstein's simile - as forming a family, the members of which may, perhaps, be grouped around a central paradigm case and linked with the latter by various direct or indirect links of logical connexion and analogy"'21]. The concept of 'brother', for example, can be defined as 'male-sibling', and therefore belongs to a class which is definable in terms of necessary and sufficient conditions. On the other 
hand, the concept of 'game' belongs to a class which is not definable in terms of necessary and sufficient conditions.

But Bambrough argues that the distinction between different kinds of complex concepts is not the point that Wittgenstein is concerned with. He holds that even if a concept is definable in terms of necessary and sufficient conditions, this does not prove that the concept is not a family concept. Because the features mentioned in the definitions are, or must ultimately be defined in terms of family concepts, and this makes the defined concept a family concept as well. Thus, according to Bambrough, if a concept is definable in terms of other concepts, at least one of which is a family concept, the defined concept is a family concept as well.

It may be argued[22] that one could also interpret the concept of family resemblances as a relative concept, and say that the concept of 'brother' is not a family concept in relation to the concepts of 'male' and 'sibling', if it is definable in terms of these concepts. But if one or both of the latter concepts is a family concept in relation to other features, the concept of 'brother' can be said to be a family concept in relation to these features.

But Bambrough does not regard the concept of family resemblances as a relative concept. He argues that the fact that some concepts can be defined does not refute his thesis that all concepts are family concepts, because a definition is not ultimate. The terms occurring in the definiens must be defined just as well as the term that is our definiendum. And the terms occurring in the latter definions must be defined in their turn, and on ad infinitum. "Even a concept which can be explained in terms of necessary and sufficient conditions can not be ultimately explained in such terms. To satisfy the craving for an ultimate explanation of "brother" in such terms it would be necessary to define "male" and "sibling", and the words in which "male" and "sibling" were defined, and so on ad infinitum or ad impossible." [23]

\subsection{Wittgenstein's theory is not an alternative explanation}

Now let us see the theory of family resemblance is the ultimate explanation of the problem of application of general words. We may mention some geometrical terms, for example 'triangle', which have definition. A triangle is a plane figure bounded by three straight lines. But here there is no difficulty to find the common property to all triangles. The problem of infinite regress in definitions is an entirely different problem and it can be solved, more or less satisfactorily, in various ways. When Wittgenstein says that we do not find any common properties to all games, he does not talk about the difficulty of infinite regress. It we consider the concepts of empirical sciences, we do not find any problem in knowing the common properties. For example, the term water' is applied to any thing whose molecule consists of two hydrogen atoms and one oxygen atom arranged in a certain manner. But the objection against such definitions of empirical science is not that of infinite regress. That is why, scientists do not try to find out family resemblances of different specimens of water, of different metals, etc. Definitions in a deductive system are never ultimate, but are always relative to the set of primitive terms admitted in the system. In this way the infinite regress in definitions can be avoided. Thus, it may be said that the very concept of science, based as it is on the Aristotelian notion of universals, seems rejects Wittgenstein's recommendation.

The another objection raised against Wittgenstein's notion of family resemblances is that though we do not know the common property to all games, do we know the family resemblances of all games, actual or possible? If we know it then we can easily enumerate the points of resemblance. But neither Wittgenstein nor Bambrough has given an enumeration of the points of resemblance. Pitcher says: "There is a group of characteristics $\mathrm{C}_{1}, \mathrm{C}_{2}, \mathrm{C}_{3}, \ldots \ldots \mathrm{C}_{\mathrm{n}}$ which games typically have. Among these characteristics are the following: $\mathrm{C}_{1}$, there are rules which govern the activity; $\mathrm{C}_{2}$, there is a possibility of winning; $\mathrm{C}_{3}$, it is a pleasant diversion; $\mathrm{C}_{4}$, the players need to exercise certain skills; and so on." [24] But what does Pitcher mean by the word 'so on'? What value ' $n$ ' has in $C_{n}$ in this case? It means that we do not know the group of characteristics which all games and only games typically have. Thus, it is wrong to say that we apply the word 'game' to all games on the basis of their family resemblances when we actually do not and can not able to enumerate the resemblances. If it is philosophically wrong to assert that we apply the word 'game' to all games on the basis of their essence without being able to tell what this essence is, it will be equally wrong to assert that we apply the word to all games on the basis of their family resemblances when we are not able to enumerate these resemblances"[25]. Thus it is said that Wittgenstein has replaced the essence or universal by a complicated structure of resemblances which overlap and criss-cross, but he failed to make any easy way to enumerate the constituents of this structure.

\section{Conclusion}

We may begin from our everyday world of experience. The world around us, as revealed in experience, is populated by particular objects, human beings, animals and so on. These particular things and beings occupy a single region of space at a given time, and they possess many properties. This is the non-linguistic part of the world. There is also a linguistic part by which we talk about those things and beings. Thus the whole universe may be divided into two broad parts- linguistic and non-linguistic. Linguistic structure reflects the non-linguistic 
structure of the world. But how the linguistic structure reflects the non-linguistic structure properly? The linguistic structure can reflect the non-linguistic structure properly only if the reference of the constituent parts of the linguistic structure exists. We may illustrate this with the help of an example.

Let us take a sentence 'Socrates is courageous'. The truth of this sentence depends on two things- (i) what the sentence 'Socrates is courageous' actually says, and (ii) the way the world is. Both these two things are matters of structure. The sentence 'Socrates is courageous' is a matter the terms which enter into its composition and the order in which they are placed. Similarly the world is a matter of non-linguistic structure. It is a matter of how things in a certain region of the world are and how they are related to each other. Thus the truth of the sentence 'Socrates is courageous' depends on a linguistic structure and a non-linguistic structure. The sentence would be true if the linguistic structure reflects or mirrors the non-linguistic structure properly.

Now, if the linguistic structure is to reflect the non-linguistic structure properly, there must be a nonlinguistic entity correlated with the proper name 'Socrates' and there also be another non-linguistic entity correlated with the term 'courageous'. Therefore, if the sentence 'Socrates is courageous' is to be true then there must have referent of its subject term and there must have referent of its predicate term. And the referents of these two terms must be related in a way that ensures that what the sentence 'Socrates is courageous' says is true. But the two terms of the above sentence are different from each other. The term 'Socrates' is a singular term and the term 'courageous, is a general term. The term 'courageous' is a general term because it can be applied to other individuals other than Socrates, for example, 'Plato is courageous'. That means the same term 'courageous' may be predicated to the individuals, other than Socrates, of the world. Here the term 'courageous' playing a referential role in the above two sentences - 'Socrates is courageous' and 'Plato is courageous'.

Now the question is: Can we say that the referents of those two occurrences of the term 'courageous' are different from each other? The answer must be negative. Because what we say about Socrates when we predicate 'courageous' of him in the sentence 'Socrates is courageous', is the same as what we say about Plato when we predicate 'courageous' of him in the sentence 'Plato is courageous'. In other words, we may say that the referential force of the term 'courageous' is not different in the above two cases, but one and same. That means the term 'courageous' picks out one and the same entity in both the two cases such that in virtue of being related to it, both Socrates and Plato count as courageous. Hence, to determine the truth of the sentences, like 'Socrates is courageous' and 'Plato is courageous', we must have to admit a repeatable entity. This entity is not the same as the entity referred by the term 'Socrates' or 'Plato'. The term 'courageous' has as its referent a certain universal - the virtue of courage, and each of Plato and Socrates exemplifies that universal that the sentences 'Plato is courageous' and 'Socrates is courageous' are true. Therefore, we have to admit the existence of objective universals for explaining the subject-predicate discourse.

Now we may consider another type of sentences which contain abstract singular terms as subject. In our language there are different types of abstract singular terms, like 'triangularity', 'wisdom', 'courage', etc. These terms are called abstract because they do not refer to individual entity, but something else. They are singular because they play the role of a subject in a subject-predicate sentence. The abstract singular term appears to be a device for picking out a certain property or kind. We may take for example a sentence like 'Triangularity is a shape '. The sentence contains an abstract singular term triangularity' in his subject place. The truth of the sentence depends on two things-(i) the existence of the entity referred by the subject term 'tringularity', and (ii) the relation between the subject and the predicate. That means the truth of the sentence 'Tringularity is a shape' presupposes that the referent of the abstract term exists. But the entity referred by the term 'triangularity' is not the same as the individual entity referred by the term like 'Socrates', rather it is functioning as a name of a universal. Therefore, the sentence 'Triangularity is a shape' can be true if the universal, its subject term refers, actually exist. If we do not take abstract singular terms to be devices for referring to universals, we fail to give a satisfactory explanation of the sentences in which the terms appear.

\section{References}

Press, Chennai, 1997) 53
[2] H. H. Price, Thinking and Experience ( Hutchinson's University Library, London, 1953) 20
[3] L. Wittgenstein, The Blue and Brown Books( Basil Blackwell, Oxford, 1958) pp-17-20.

[4] L. Wittgenstein, Philosophical Investigations, Trans. G.E.M.Anscombe (Basil Black well, Oxford, 1972) Sects. 65-71.

[5] Ibid, Sect. 67.

[6] L. Wittgenstein, The Blue and Brown Books (Basil Blackwell, Oxford, 1958) 17

[7] L. Wittgenstein, Philosophical Investigations, Trans. G.E.M.Anscombe( Basil Black well, Oxford, 1972) Sect. 66

[8] Ibid., Sect.66

[9] Ibid., Sect.

[10] S. Bhattacharya, "Universals and Family Resemblances" as incorporated in the Doubt Belief and Knowledge ( Indian Council of Philosophical Research, New Delhi, 1987) 153

[11] S. Bhattacharya, "Universals and Family Resemblances" as incorporated in the Doubt Belief and Knowledge (Indian Council of Philosophical Research, New Delhi, 1987) 153 
[12] R. Bambrough, "Universals and Family Resemblance" as incorporated in the Wittgenstein: The Philosophical Investigations, Ed. George Pitcher ( Macmillan, London, 1986) 186-204.

[13] Ibid, 189

[14] Ibid, 191

[15] A.J.Ayer, The Problem of knowledge ( Macmillan \& Co. Ltd., London, 1958).

[16] Ibid, 5-6

[17] L. Wittgenstein, The Blue and Brown Books (Basil Blackwell, Oxford, 1958) 130

[18] L. Wittgenstein, Philosophical Investigations, Trans. G. E. M. Anscombe ( Basil Black well, Oxford, 1972 ) Sect.73.

[19] R. Bambrough, "Universals and Family Resemblance" as incorporated in the Wittgenstein: The Philosophical Investigations, Ed. By George Pitcher ( Macmillan, London, 1986) 193.

[20] H. Wennerberg, "The concept of family resemblance in Wittgenstein's latter philosophy", Theoria, Vol. XXXIII, $1967,124$.

[21] P.F.Strawson, Individuals: An Essay in Descriptive Metaphysics (Methuen \& Co., London, 1959) 11

[22] H. Wennerberg, "The concept of family resemblance in Wittgenstein's latter philosophy", Theoria, Vol. XXXIII, $1967,124$.

[23] R. Bambrough, "Universals and Family Resemblance" as incorporated in the Wittgenstein: The Philosophical Investigations, Ed. George Pitcher (Macmillan, London, 1986) 198.

[24] G. Pitcher, The Philosophy of Wittgenstein (Prentice Hall of India Pvt. Ltd., New Delhi, 1985) 220.

[25] Ibid, 220 